\title{
Mathieu Labeau, Une nouvelle génération de romanciers africains? Débats et enjeux (2000-2010)
}

\section{Elena Fermi}

\section{(2) OpenEdition}

1 Journals

\section{Édition électronique}

URL : http://journals.openedition.org/studifrancesi/1493

DOI : 10.4000/studifrancesi. 1493

ISSN : 2427-5856

Éditeur

Rosenberg \& Sellier

\section{Édition imprimée}

Date de publication : 1 décembre 2015

Pagination : $642-643$

ISSN : 0039-2944

\section{Référence électronique}

Elena Fermi, « Mathieu Labeau, Une nouvelle génération de romanciers africains? Débats et enjeux (2000-2010) », Studi Francesi [En ligne], 177 (LIX | III) | 2015, mis en ligne le 01 décembre 2015, consulté le 06 janvier 2021. URL : http://journals.openedition.org/studifrancesi/1493 ; DOI : https://doi.org/ 10.4000/studifrancesi.1493

Ce document a été généré automatiquement le 6 janvier 2021.

\section{(c) $(1) \ominus$}

Studi Francesi è distribuita con Licenza Creative Commons Attribuzione - Non commerciale - Non opere derivate 4.0 Internazionale. 


\title{
Mathieu Labeau, Une nouvelle génération de romanciers africains? Débats et enjeux (2000-2010)
}

\author{
Elena Fermi
}

\section{RÉFÉRENCE}

MATHIEU LABEAU, Une nouvelle génération de romanciers africains? Débats et enjeux (2000-2010), Paris, Anibwe, 2014, pp. 153.

1 Ce volume en petit format de poche aborde la question de la nouvelle génération de romanciers francophones issus des anciennes colonies (Afrique, Caraïbes, Océan Indien) qui, depuis une quinzaine d'années désormais, a fait son apparition sur la scène littéraire du vieux continent et qui a fait l'événement lors de la rentrée littéraire 2014. C'est plus précisément sur les romanciers africains que l'auteur, Mathieu LABEAU, se focalise dans ce petit ouvrage: il affirme vouloir poser un regard global sur la nouvelle génération afin de mettre en relief à la fois son positionnement par rapport à la littérature africaine et mondiale, sa relation avec ses prédécesseurs et ses démarches esthétiques spécifiques. L'approche adoptée étant celle d'ouvrir un débat que l'auteur sait être complexe, donc susceptible d'ultérieurs développements, l'analyse se focalise sur quelques écrivains considérés comme des modèles: le franco-djiboutien Abdourahman Waberi, les togolais Kossi Efoui et Sami Tchak, le congolais Alain Mabanckou et le camerounais Eugène Ebodé. L'étude de quelques œuvres de référence de ces auteurs, basée sur les théories littéraires plus récentes énoncées par Dominique Maingueneau, offre aux lecteurs un simple outil de consultation.

Le volume s'ouvre avec un panorama rapide de l'évolution du champ littéraire africain. Labeau y relève les changements de perspective que la littérature de ce continent a subis à partir des années trente et du mouvement de la Négritude-lorsque les intellectuels étaient encore des colonisés et que, voulant se démarquer du discours du 
colonisateur, ils trouvaient leur autonomie dans la référence continuelle à leur terre d'origine - jusqu' à aujourd'hui, où les récits africains sont engagés dans l'épopée du monde contemporain, en instance de mondialisation, dont ils brossent les contours, les failles et les promesses. Les romanciers de la nouvelle génération rejettent l'engagement en tant que composante obligatoire de leur écriture, prennent leur distance du continent africain pour s'ouvrir à une perspective universelle et adoptent dans leurs œuvres une approche intertextuelle ouverte à des auteurs d'origines, d'époques, de genres tout à fait différents. Ils ont pris confiance en eux, ont conscience de la valeur de leur œuvre dans le panorama mondial et veulent ainsi se légitimer. Leur production se caractérise par ailleurs du fait d'être une littérature de la diaspora, de l'exil, de l'émigration, car la plupart d'entre eux ne vit plus en Afrique. L'exil est cependant vécu et représenté par ces auteurs de manière apaisée par rapport à leurs aînés; il représente une opportunité, une occasion enrichissante plutôt qu'un événement tragique. La nostalgie du «pays natal», la nécessité d'un retour aux sources ne leur appartient plus. Ils ne sont pas non plus centrés sur la métropole et sur Paris comme sur les centres d'où la nouvelle littérature doit forcément rayonner mais, déclarant la mort de la francophonie telle qu'elle était conçue et institutionnalisée, proclament la naissance d'une «littérature monde en langue française» caractérisée par le multicentrisme. Par ailleurs, il est évident que quelques questions se posent par rapport au rôle joué par les maisons d'édition (parisiennes pour la plupart), dans les choix faits par les auteurs, ainsi que sur le poids du lectorat (pour la plupart occidental ou africain occidental), visé par les auteurs. Cependant, l'évolution des rapports culturels entre l'Afrique et l'Occident est indéniable et cette relation se bâtit sur des bases inédites auparavant: celles de l'hybridité, d'identités non figées, sans cesse en changement.

3 Les sujets des romans et des récits ont eux aussi subi des modifications au cours des décennies. Si, à l'époque coloniale, le sujet privilégié était la dénonciation de la colonisation, avec l'indépendance les écrivains ont plutôt ressenti le besoin de mettre l'accent sur les pouvoirs qui en étaient issus pour enfin se focaliser sur la critique de la tradition africaine et des conditions d'immigration; les textes romanesques étaient donc des miroirs de la société africaine et, de ce fait, ils adoptaient une perspective réaliste qui a été mise de côté par la nouvelle génération. Beaucoup de jeunes romanciers choisissent de parler à la première personne, donnant toute sa place à l'instance narrative où le rêve, l'imaginaire, font souvent irruption pour brouiller les pistes de compréhension, pour faire sauter les frontières avec la «réalité». L'Afrique reste, même chez eux, protagoniste avec ses malheurs, l'écriture n'abandonne pas le «style oral» ni la recherche de la tradition comme base d'une identité mais tout cela est filtré à travers un regard subjectif qui finit par s'affirmer sur la réalité objective et par faire ressortir l'incapacité des mots à dire la douleur du monde. Cependant, le discours littéraire ne peut pas faire abstraction du contexte dans lequel il se développe et doit nécessairement se définir par rapport à des enjeux du champ. Ceci est d'autant plus vrai pour les romanciers africains qui sont encore contraints de se définir non seulement par rapport à leurs prédécesseurs mais aussi par rapport aux écrivains occidentaux.

4 Ce petit volume s'adresse à tout type de public. Tout en étant écrit par un spécialiste des littératures francophones, il n'a pas la prétention d'être exhaustif, ni celle de fournir des outils spécifiques aux chercheurs. Il permet une lecture rapide, utile pour se faire une idée générale des enjeux de cette thématique. Il aurait peut-être fallu 
ajouter, en conclusion du volume, une bibliographie essentielle qui aurait facilité la tâche aux lecteurs désirant approfondir leurs connaissances à ce sujet. 